\title{
СОН, ЕДА И РАЗГОВАРИВАЯ: СИМВОЛИЧЕСКАЯ СВЯЗЬ
}

\section{ОРИГИНАЛЬНАЯ СТАТЬЯ}

PALLADINO, Ruth Ramalho Ruivo1, SOUZA, Luiz Augusto de Paula², PALLOTTA, Mara Lucia ${ }^{3}$, COSTA, Rogério da ${ }^{4}$, CUNHA, Maria Claudia ${ }^{5}$

PALLADINO, Ruth Ramalho Ruivo. Et al. Сон, еда и Разговаривая: символическая связь. Revista Científica Multidisciplinar Núcleo do Conhecimento. Год 06, эд. 08, Vol. 06, с. 153-170. Август 2021 года. ISSN: 24480959, Ссылка доступа: https://www.nucleodoconhecimento.com.br/психология/символическая-связь, DOI: 10.32749/nucleodoconhecimento.com.br/ru/98238

\section{СВОДКА}

Сон, питание и язык являются столпами здоровой жизни детей, переплетаются с рождения и составляют динамическую структуру развития ребенка. Это эфффекты взаимозависимых условий: органических, психических и социальных, которые вовлекают ребенка и являются результатом, одновременно, органического и символического наследования. Последний переопределяет и модулирует взаимодействие ребенка с окружающей средой, особенно с другим человеком, который там находится. Это наследие будет рисовать модели

\footnotetext{
${ }^{1} \mathrm{PhD}$ в области клинической психологии, PhD профессор аспирантуры в области коммуникации и здоровья человека, факультет гуманитарных наук и здоровья, PUC-SP (ORCID: https://orcid.org/0000-00018466-838X).

2 Доктор философии в области клинической психологии, профессор аспирантуры в области коммуникации и здоровья человека, факультет гуманитарных наук и здравоохранения, PUC-SP (ORCID: https://orcid.org/0000-0003-4968-9753).

${ }^{3}$ Аспирант в области коммуникации и здоровья человека в PUC-SP (ORCID: https://orcid.org/0000-00015986-9657).

${ }^{4}$ Кандидат философских наук, профессор аспирантуры по коммуникации и семиотике, PUC-SP (ORCID: https://orcid.org/0000-0002-6807-4263).

${ }^{5}$ Доктор философии в области клинической психологии, профессор аспирантуры в области коммуникации и здоровья человека, факультет гуманитарных наук и здоровья, PUC-SP (ORCID: https://orcid.org/0000-0003-3198-6995).
}

$\mathrm{RC}: 98238$

Доступно в:

https://www.nucleodoconhecimento.com.br/психология/символическая-связь 
поведения и поведения, которые часто могут способствовать изменениям, которые в некоторой степени ставят под угрозу общее развитие ребенка. В детской клинике описание развития отличий, от самых мягких до самых тяжелых, включает, как правило, аспекты питания, сна и языка, что предполагает, таким образом, базовую триаду, ставя под сомнение клиницистов о возможности существования, более чем простого совпадения, корреляции между фундаментальными биологическими функциями. Если это так, то для клиницистика будет важно соответствовать этой точке зрения, поскольку последствия, вероятно, будут определять особенности диагностических и лечебных процедур. В этом направлении стоит углубить и обсудить развитие этих фрункций (сон, диета, язык), стремясь прояснить их конститутивную корреляцию, связь между ними.

Ключевые слова: Язык, Еда, Сон.

\section{1. ВВЕДЕНИЕ}

$\mathrm{CoH}$, питание и язык являются столпами здоровой жизни детей, переплетаются с рождения и составляют динамическую структуру развития ребенка.

Такое переплетение, однако, не является единодушным постулатом, в проектах по описанию и пониманию этой триады либо каждая часть берется отдельно или, тогда, указывается на привилегию одной стороны над другой, то есть это были бы отношения, которые нельзя определить как импликации.

Чтобы подумать о подтексте, необходимо предположить, что сон, еда и речь связаны с телом, но телом, которое требует имени, субъективного тела и, следовательно, тела, зачисленного символом: в связи между собственным именем и телом есть в прочтении этой черты нечто, что артикулируется через присвоение, само по себе, что не является таким очевидным и простым элементом в человеческой конституции (LEITE, 2008, с.16). Как

$\mathrm{RC}: 98238$

Доступно в:

https://www.nucleodoconhecimento.com.br/психология/символическая-связь 
представляется такое присвоение органа, которое исходит от его собственного органа при его назначении? Назвать тело - значит распознать его в символическом поле, эффректе бесконечных артикуляций, действий и переплетаться.

Сон, питание и речевые паттерны являются эфффектами взаимозависимых условий: органических, психических и социальных, которые вовлекают ребенка и являются результатом, одновременно, органического и символического наследования. Последний переопределяет и модулирует взаимодействие ребенка с окружающей средой, особенно с другим человеком, который там находится.

Для младенцев эта среда может быть представлена, привилегированно, материнской фригурой, матерью и, стоит отметить, это даже не обязательно биологическая мать или опекуны, а асановый материнский пример, другой человек, который пишет «близкий кто-помощь», фрейдистский nebensmench, как объясняет Cabassu (2003). Тот, кто более чем гарантирует выживание детского организма, признает его субъектом, составляет связь между желанием (материнским) и словом, из которой субъективность и социальные отношения становятся возможными и начинаются для младенца, называя его тело и его надпись в тексте принадлежности и общительности.

Если, как мы уже говорили, сон, еда и язык являются столпами жизни ребенка, то их подтекст зависит, следовательно, от материнских высказываний, обращенных к нему, но только в том случае, если они - утолить голод, согреться от холода, упаковать ко сну... - сопровождаются неанонимным желанием (STORK, LY, MOTA, 1997, с. 34): это наличие другого, института материнских отношений.

Кроме того, важно знать, что необходимо признать в материнских отношениях культурный смысл, в равной степени определяющий, потому что матери

RC: 98238

Доступно в:

https://www.nucleodoconhecimento.com.br/психология/символическая-связь 
интерпретируют и реацируют на проявления [...] ребенка в соответствии с нормами общества, к которому они принадлежат, даже если их реакции также модулируются личной психической динамикой (CISMARESCO, 1997, стр. 267).

Это условие предполагает, в более широком смысле, центральное место функции континентальной семьи, для которой концепция «Я-кожа» Anzieu (1989) может быть поучительной, поскольку она относится к границам между биологическим и символическим, а для ребенка еe создание отвечает на потребность в наристической оболочке и обеспечивает психическому аппарату определенность и постоянство основного благополучия (op. cit., p. 44). Это чувство безопасности будет фундаментальным для чувства принадлежности, основным для построения идентичности ребенка.

Это наследование, одновременно органическое и символическое, переданное в отношениях ребенка с другим, связанное - конечно - с органическим наследованием, будет рисовать модели поведения и поведения, которые часто могут способствовать изменениям, которые в какой-то степени ставят под угрозу общее развитие ребенка.

В детской клинике описание развития неурядицы, от самых легких до самых тяжелых, включает, как правило, аспекты питания и сна (WINNICOTT, 1975; MADEIRA, AQUINO, 2003; SANTOS, 2004; JERUSALINSKY, 2004).

Тот фракт, что эти симптомы почти всегда совпадают друг с другом, ставит под сомнение возможность существования, помимо простого совпадения, корреляции между фундаментальными биологическими функциями.

Более того, в клинических описаниях нарушений развития речи часто встречаются сообщения о проблемах с питанием (PALLADINO, CUNHA, SOUZA, 2007) и сном, что предполагает триаду корреляций.

$\mathrm{RC}: 98238$

Доступно в:

https://www.nucleodoconhecimento.com.br/психология/символическая-связь 
Тем не менее, и часто, различные области исследований развития не разделяют идею о значительной корреляции между такими функциями, и часто проблемы сна, кормления и языка рассматриваются отдельно. Когда это так, при наличии изменений в развитии, явление принимается как коморбидность.

Есть исключения и такое преобладание, это фракт, имеющее отношение к психоанализу и определенным подходам психологии (GROMANN, 2002), а также к небольшой части исследований дисциплин, которые ведут диалог с обоими, такими как логопедия, психиатрическая медицина, неврология и эндокринология. Эти исключения вдохновили на дальнейшие размышления.

Предположение о корреляциях между функциями позволяет уточнить симптоматологическое выравнивание, наблюдаемое между приемом пищи, сном и языковыми симптомами в раннем детстве. Если это так, то для клиницистика будет важно соответствовать этой точке зрения, поскольку последствия, вероятно, будут определять особенности диагностических и лечебных процедур.

В этом направлении стоит углубить и обсудить развитие этих функций (сон, диета, язык), стремясь прояснить их конститутивную корреляцию, связь между ними.

\section{2. ЕДА И ЯЗЫК: СЮРПРИЗ В НАБЛЮДЕНИИ}

Некоторое время назад в повседневной жизни детской клиники наблюдение за силой indicia начало задавать нам вопросы.

Это происходило перед лицом повторяющихся родительских рассказов о проблемах с питанием в случае, называемом в процедурах оценки или даже в последующем контроле за терапевтическими планами в случае детей с различными проблемами языкового развития. При работе с этими детьми рано или поздно возникали жалобы на кормление, переходя от идиосинкразий к

RC: 98238

Доступно в:

https://www.nucleodoconhecimento.com.br/психология/символическая-связь 
нарушениям глотания, и их настойчивое повторение было тем, что завоевало место в нашем клиническом слушании, и с этим показательная ценность наблюдения приобрела актуальность.

Основываясь на этих наблюдениях, мы структурировали исследование с выборкой из 35 пациентов, и полученные доказательства прояснили важное соответствие между языковыми и пищевыми проблемами, предполагая значительную корреляцию между ними (PALLADINO, CUNHA, SOUZA, 2004 и 2007).

Психоаналитическое прочтение проблемы, предложенное Французский журнал ортофонии (2004), позволило теоретически охватить результаты этого исследования, что привело нас к мысли о корреляции между языковыми проблемами и проблемами питания в рамках понятия устности, как это было предложено Thibaut (2006, с. 115): оральная зона - это одна из эрогенных зон тела, то есть пространство, поддерживаемое влечением, в котором многие фрункции переплетены в общем плане символического функционирования. В этом смысле рот (орган) - это территория еды, языка и привязанности.

Другими словами, устная зона - это соматическое поле, в котором оральная, как психический план, символически переплетает пищу и язык.

\section{3. ЕДА, ЯЗЫК И СОН: НОВАЯ АРТИКУЛЯЦИЯ}

Это концептуальное перепозиционирование направило и развернуло наше клиническое слушание в других пространствах, что привело нас, в последнее время, к переработке отношений пищи и языка от включения сна, образуя конститутивную триаду ребенка. Сон также был включен, потому что он также является главным героем в фундаментальной сцене конституции ребенка (PALLADINO, 2016, 2018). Сон связан со сценой кормления ребенка и является частью родительских повествований в случае детей с проблемами языкового

$\mathrm{RC}: 98238$

Доступно в:

https://www.nucleodoconhecimento.com.br/психология/символическая-связь 
развития, хотя все еще непрозрачны, то есть считаются бесполезными или с небольшой ценностью с точки зрения риска для развития ребенка.

Предполагая конститутивную корреляцию между этими фрункциями, необходимо будет уточнить симптоматологическое выравнивание, наблюдаемое между симптомами еды, сна и языка, а также проанализировать возможные последствия в диагностическом и лечебном поведении в этих случаях.

Сон, фундаментальная биологическая функция, важная для восстановления энергетического метаболизма мозга и консолидации памяти (CABALLO, NAVARRO, SIERRA, 2002), а также для самого психологического баланса, является результатом постепенной временной, структурной и физиологической организации сна. -Ритм бодрствования (GEIB, 2007; PIAULINO DE ARAÚJO, 2012.) Это состояние функционирования мозга с двумя различными и измеримыми фазами: Спать REM (Rapid Eye Movement) и сон NREM (No Rapid Eye Movement). Различия заключаются в основном в метаболических механизмах с соответствующими изменениями фризиологических процессов и постуральных состояний. Во время быстрого сна наблюдается повышение уровня метаболизма, определенная атония мышц, снижение температуры тела, сбалансированный ритм дыхания (с небольшими и кратковременными апноэ), быстрые движения глаз, а в случае детей могут возникать плач / улыбка / стоны. Во сне NREM наблюдается снижение уровня метаболизма, снижение частоты дыхания и подвижности тела (JOHN, 2000). В этой фразе происходит обширная работа по клеточной регенерации, а в другой, фраза REM, в основном психологическая регенерация, поскольку именно здесь происходит большая часть сновидений.

REM и NREM сон чередуются, а также состояния сна и бодрствования чередуются. Цикл между состояниями сна и бодрствования, вначале только биологически детерминированный, начинает организовываться еще в фазе плода и его конституция тесно связана с развитием центральной нервной

$\mathrm{RC}: 98238$

Доступно в:

https://www.nucleodoconhecimento.com.br/психология/символическая-связь 
системы (GEIB, 2007). Постепенно эта организация страдает от воздействия экзогенных раздражителей, таких как интенсивное сияние, разнообразные звуки и, прежде всего, присутствие человека, заставляя цикл сна-бодрствования иметь ритм, отмеченный этой двойной интерференцией - эндогенной и экзогенной.

При рождении режим сна ребенка - по существу фризиологический - проще, с двумя состояниями, активным (REM-coH) и тихим (NREM-coH), в ритме снабодрствования, называемом ультрадиановым, еще не доминирующим чередованием дня и ночи. Циклы чередуются в более короткое время, и в первые месяцы преобладает активное состояние: малыш спит в любой момент и очень легко просыпается, а бодрствование объявляется плачем и только позже наблюдается спокойное бодрствование. Со временем этот ритм видоизменяется окружающей средой, вызывая некоторую анархическую атипику, то есть изменения в начале полностью дезорганизованные и дезорганизующие цикл сна не только светящимися и слышимыми раздражителями, но главным образом действиями человека, которые заканчиваются модуляцией ритма, который, в конце концов, становится цикардиано, с длительными ночными периодами спокойного сна или даже более спокойного бодрствования. (PIAULINO DE ARAÚJO 2012; JOHN, 2000)

Преобладающим действием человека в вопросе сна младенцев является кормление по двум основным причинам: оно часто предшествует моменту сна ребенка, помимо того, что оно полагается на другого человека для своей эфффективности. Таким образом, то, что вначале имеет определение только эндогенного, начинает страдать от влияния внешней среды. Именно здесь ультрадианские и циклардианские ритмы консолидируются и начинают чередоваться, первый для управления распределением фаз сна, а второй для состояний сна и бодрствования, обретение сна ночью и бодрствования днем (PIAULINO DE ARAÚJO, 2012; JOHN, 2000).

$\mathrm{RC}: 98238$

Доступно в:

https://www.nucleodoconhecimento.com.br/психология/символическая-связь 
Взяв малыша к себе на колени, чтобы кормить его грудью, мать предлагает ему непревзойденное аффрективное поле: удовольствие от того, что он сбрасывает молоко, слышит слова, испытывает трение тела другого, это наслаждение заставляет его заснуть, отдать себя.

Таким образом, сон и пища выходят за рамки необходимости и, более того, представляют собой окончательное переплетение (PENHA, 2002; FÉDIDA, 1977). Как уже упоминалось, эти функции ребенка зависят от другого человека для их должной реализации и по этой причине приобретают символический характер, конформируясь как психические переживания. Такие переживания, в общем-то удовольствия, оставляют психические следы и мозговые ступни, создавая мощные воспоминания, которые приглашают испытуемых к общению с другим.

Мать будет кормить ребенка грудью, говорить и/или петь ему, гладить его, что, наряду с сытости, успокаивает ребенка и способствует сну. Однако голод через некоторое время пробудит ребенка, повторив цикл бодрствования-сна.

Это означает, что этот непрерывный цикл будет не только эфффектом органического ритма, но и психического ритма, напечатанного матерью (FARIAS, 2004), через ее заботу.

Другими словами, грудь (или бутылка) становится полем обмена и местом для погружения в сон (FOLINO, LOPES DE SOUZA, 2013), разговоры / жужжание и покачивание составляют этос этих практик сна. Laznik-Penot (1997, с. 37) показал решающее значение материнской мелопеи - музыки голоса матери, говорящей с младенцем. Эта сцена заботы, в свою очередь, подразумевает пищу, придает ей также символическое существование.

В конечном счете, этот интимный и повторяющийся ритуал, который включает в себя тело и слова, сон и еду, будет представлять собой фундаментальную

RC: 98238

Доступно в:

https://www.nucleodoconhecimento.com.br/психология/символическая-связь 
сцену гуманизации, составляющую план отношений, в котором налагается связь между ребенком и его матерью. Фактически, эта перспектива подтверждает идеи Спиноза (2007) о привязанностях и их последствиях с точки зрения радости или печали: мать и ребенок влияют и подвержены влиянию друг друга, что создает сеть афрфективных связей, которые составляют их как таковые, часто расширяя способность действовать в этих единичных отношениях и во всех других. Возросшая способность действовать в мире это то, что Спиноза называет радостью.

Однако привязанности между матерью и ребенком не всегда являются потенциальными, иногда может случиться обратное. Давайте рассмотрим относительно распространенный пример: матери, которые переживают baby blues (доброкачественную, преходящую, потенциально продуктивную депрессию, поскольку она является частью изменений, вызванных рождением ребенка) и не находят возможности развития и принятия со стороны социальный контекст, который часто признает рождение ребенка только по ощущениям счастья и полноты, которые в культурном отношении оно должно вызывать (FOLINO, LOPES DE SOUZA, 2013).

Эти депрессивные матери тратят меньше времени на то, чтобы смотреть, трогать, разговаривать со своими детьми, показывая меньшую отзывчивость, спонтанность и более низкие показатели активности со своими детьми. Послеродовая депрессия способствует тому, что диада становится асинхронной, в той степени, в которой мать мало или не реагирует (SERVILHA, RAAD BUSSAB, 2015). В этот период аффективный процесс между матерью и малышом не повышает потенцию обоих, наоборот, снижает ее, а может даже разворачиваться, в некоторых случаях, психические проблемы или расстройства для матерей и для развития малыша. Уменьшение силы действовать - это, в свою очередь, то, что Спиноза называет печалью.

$\mathrm{RC}: 98238$

Доступно в:

https://www.nucleodoconhecimento.com.br/психология/символическая-связь 
Принципиально важно, что цикл кормления-зазубрин-сна представляет собой разнообразные психические переживания для малыша, которые подразумевают неоднозначные чувства для малыша: кормление и закарцерация становятся пространством и временем взаимодействия матери и ребенка, а сон разделения между ними - при засыпании малыш помещается в кроватку. Сон будет представлять собой разрез, интервал или разрыв в исходной связи между ребенком и его матерью. Ритуал сам по себе содержит двусмысленность между принятием и разделением. Такая позиция матери, двойная, неоднозначная, деликатная, инсценируется, когда она поет и ребенок засыпает, чтобы его поместили в колыбель: любящий подход и разлука.

Постепенно мать наносит удары - возможность закрепить бодрствующее состояние - а также вводит заменители, которые стоят между ее собственным телом и телом малыша в качестве заменителей ее присутствия: пустышки, кастрюли и игрушки, даже слово метафорическое, то, которое приводит мать, представляет ее ребенку. Эти заменители вставляются для работы смещений в сращенные отношения, которые составляют первые дни связи между матерью и ребенком, являются опорой для ребенка, чтобы противостоять страданиям разлуки, которую объявляет сон, чувство, что сон определяет отсутствие матери, лишение окружающей среды, которая обеспечивает еe жизнь и удовольствие.

Следует отметить, что необходимость работы поездок на работу для засыпания сохраняется и обновляется в зрелом возрасте, в ритуалах, предшествующих сну: ванны, чаи, чтения.....Как будто эти ритуалы снимают «опасность», которую налагает одиночество сна, и гарантируют своеобразную страховую защиту от онемения. Некоторые пожилые люди проявляют трудности в засыпании из-за страха смерти (GEIB, et al, 2003): тоска по потере своего и мира. Взрослый человек имеет интернализованное фрункционирование материнского экземпляра ассегурадора, управляя перемещениями, создавая заменители

$\mathrm{RC}: 98238$

Доступно в:

https://www.nucleodoconhecimento.com.br/психология/символическая-связь 
того, кто был первым хранителем сна, теперь бессознательно возрождается, например, массажами, чувственными практиками, приемом пищи, напитков или лекарств.

В детстве, в каждой культуре и варьирующейся из-за социальных и экономических условий, есть несколько способов обойти эту боль сна (как матерью, так и ребенком): совместная кровать (полная или частичная), общая комната и наличие (необходимого) ночного грудного вскармливания (BLAIR, 2008).

Но, важно отметить, клиницисты и исследователи склонны ссылаться на так называемый «золотой стандарт» младенческого сна в западных обществах так называемый развитый, паттерн искали рано: односпальная кровать, отдельная комната от родителей, отсутствие ночного кормления.

Тем не менее, существуют различные предупреждения относительно проблемы сна, поскольку он также импортирует участников сцены и привычки сна, составляющие внешние циклы сна (GEIB, 2007). Минимально предполагается, что для ребенка, который не засыпает или имеет последовательные пробуждения, может быть мать, которая не думает отделять свое тело от тела своего ребенка, перестать с ним разговаривать, напевать для него, вырезать его...

Одной из возможностей преодолеть эту тоску является желание сна, случай, когда то, что было потеряно или отсутствовало, может подняться онирно.

Первоначально исследования постулировали, что сны представляют собой исключительную активность фразы быстрого сна. Тем не менее, более поздние исследования показывают, что нет никакой исключительности, хотя в фазе REM преобладает эта активность, с признанием учеными, что она

RC: 98238

Доступно в:

https://www.nucleodoconhecimento.com.br/психология/символическая-связь 
предназначена для обеспечения того, чтобы сон выполнял свою регенеривную функцию (GROMANN, 2002).

Сны - это эфффект оцепенения цензуры, которые препятствуют ощущениям, чувствам и поступкам; цензура, которая населяет сознание каждого, нарушая как бодрствование, так и сам сон. Онемение освобождает место для того, что называется сновидением, то есть для построения мыслей, свободных от запрета. По этой причине сновидения выполняют психическое восстановление, столь же важное, как и фризическое восстановление, действующее в основном в фразе NREM.

В развитии ребенка постепенно соблюдаются фразы сна, чтобы правильно организовать сон, делая его полотном для сновидений: от фризиологического до символического сна. Малышу нужно простроить путь между приемом пищи, закрытием глаз, потерей матери (вне поля зрения!) и встретить ее снова во сне (PENHA, 2002).

Что касается сна, то существует золотой стандарт для продуктов питания, производимых в основном культурно (даже если там учитывать органические аспекты). На Западе: грудное вскармливание в течение не менее шести месяцев, естественное отлучение от производства, введение пасты и твердых веществ, путь, который, быстро, должен перейти от теплой жидкости, неопределенного вкуса, к твердой, горячей, соленой пище, в знакомых сценах, предполагающих индивидуальное исполнение.

Однако, как и в вопросе сна, на карту поставлено несколько материалов, которые индивидуализируют сцену и заслуживают внимания (JERUSALINSKY, 2004; MADEIRA, AQUINO, 2003).

Можно провести параллель и сказать, что для ребенка, который плачет, душится, румина, рвет и/или отказывается от пищи, помимо возможных

$\mathrm{RC}: 98238$

Доступно в:

https://www.nucleodoconhecimento.com.br/психология/символическая-связь 
анатомофизиологических проблем, может быть мать, которая с трудом позиционирует себя как другая страховая застраховка субъекта в конституции, неправильно выполняя сцену еды, без радости или даже с грустью.

Метафрорическая сцена этой трудности представлена в отлучении отнятие, постепенном процессе, который заслуживает деликатности, поскольку он поддерживается символическими операциями разделения и, следовательно, не является «естественным» событием, очевидным, поставка пищи и переход одних типов к другим всегда тихие.

\section{4. СТРУКТУРА ЯЗЫКА}

Язык - это человеческая деятельность, преобладающая в вопросах сна и кормления. Обе фрункции представляют собой символический опыт в словах матери и в детских словах, воображаемых матерью. В песне, в сюжете, в междометиях матери и в сахаре, во взгляде, в закрытии глаз, в несдельных звуках, которые являются «высказываниями» малыша. Диалогическая сцена выполнена как «игра слов», в бактинской интерпретации. Основополагающий диалог, который сохраняется и знаменует собой вхождение субъекта в язык, территория встреч и противостояний субъективности: полифоническое столкновение различных социальных инстанций, конфликтующее сосуществование голосов и эффректы смысла. Это происходит с самого начала, начиная с самой полифонии материнской речи, основанной на амбивалентной позиции перед вашим новорожденным ребенком.

Речь матери не вызывает прямого воздействия на ее малыша, но достигает его через эффрект, который она спровоцировала в себе (CORIAT, 2000), что делает отношения с малышом раскрывающим полем, которое может запустить ее в переживание чистого удовольствия, или нет. То, что сразу фокусируется на ребенке, это голос матери, эта материнская мелодия, музыкальное и поэтическое измерение с афффективными значениями (LAZNIK-PENOT, 2013),

$\mathrm{RC}: 98238$

Доступно в:

https://www.nucleodoconhecimento.com.br/психология/символическая-связь 
которое вовлекает и поддерживает ребенка, полностью зависимого. Мелодия, которая создает сцену кормления и оцепенения. Ребенок уделяет особое внимание голосу матери и, в ее отсутствие, любому мелодичному голосу, который имеет привязанности. Именно так он компонует взаимодействие с другими людьми в своем окружении.

Этот нежный голос через тонкости, динамику и грубость (изменение чувств и ощущений) является пространством для спонтанного выражения материнского бессознательного (FÓNAGY apud LAZNIK-PENOT, 2013). По этой причине важно отметить, производятся ли в этой мелодичной речи сладкие слова, или из-за материнской амбивалентности этот голос может также производить в своих шумах другие (слова), которые довольно странны (LAZNIK- PENOT, 2013, с.130). Кажется, это способ понять, когда взаимодействие не удается.

Мелодичная колыбель речи матери приветствует ребенка и погружает его в символическое измерение человеческого существования, как предупреждает Melgaço (2013, с. 10), когда говорит, что процесс цивилизации подчеркивает силу слов.

Под голос матери ребенок представляет себя своим взглядом, своими движениями, звуками и спиной и спиной между двумя играми взаимодействия, купаясь словами отношений, в которые поставлены мать и ребенок.

Это первичные конститутивные времена, в которые могут быть тупики и, когда они вылупляются, симптомы, выражения, которые находят поток в пище, сне и языке, в той мере, в какой эти фрункции касаются, в основном, отношений между ребенком и его матерью.

В этой степени и, наконец, суть вопроса лежит не в матери или в ее ребенке, а в отношениях между ними, в процессе не сходства, а идентификации, отмеченного первоначально тем, что, когда младенцы еще не говорят, эта

RC: 98238

Доступно в:

https://www. nucleodoconhecimento.com.br/психология/символическая-связь 
реляционная сфрера разбивается, прежде всего, психическими процессами матери, что было бы первым случаем конституции психической логики и, Как указывает Vorcaro (2005, стр. 24), из значительного роя, производимого в области Другого, в который погружено живое существо, «предыдущее место» субъекта возникает как эфффект языка. Таким образом, то, что остается без сознания у матери, более восприимчиво $к$ надписям $и$ откровениям младенца (CHAVES, 2013, стр. 228).

Сон, еда и, почему бы не указать, взгляд/взгляд - первые «слова» ребенка это этап откровений для матери и ее малыша. В этих единичных отношениях расцвет столпных функций жизни ребенка будет зависеть от долгого пути между положением объекта(от и к матери) и положением субъекта.

\section{5. ОКОНЧАТЕЛЬНЫЕ СООБРАЖЕНИЯ}

Как уже говорилось, это исследование выходит из клиники и, мы предполагаем, что оно должно вернуться в нее. То есть перед лицом жалоб, связанных со сном, пищевыми и языковыми расстройствами, важно, чтобы медицинский работник был в состоянии позаботиться о возможных требованиях, вытекающих из символической артикуляции между этими тремя измерениями; артикуляция присуща фрункционированию человека, когда предполагается неразрывность между языком, телом и психизмом.

Если это так, возможно, сон также может быть включен в будущие исследования сложного символического подтекста, проработанных здесь.

\section{ИСПОЛЬЗОВАННАЯ ЛИТЕРАТУРА}

ANZIEU, D. O Eu-pele. São Paulo: Casa do Psicólogo, 1989.

BLAIR, O. S. O co-leito em perspectiva. Jornal de pediatria, 84(2), 99-101, 2008.

$\mathrm{RC}: 98238$

Доступно в:

https://www.nucleodoconhecimento.com.br/психология/символическая-связь 
CABALLO, V. E., NAVARRO, J. F. e SIERRA, J. C. Tratamento comportamental dos transtornos do sono In: CARLSON, N. R. Fisiologia do Comportamento. 7ed, SP: Manole, 2002.

Cabassu G. Palavras em torno do berço. In: Wanderley D. B. (org) Palavras em torno do berço. Salvador, Ágalma, 2003.

CHAVES, M. P. C. T. O lugar do analista na clínica com bebês. In: BUSNEL M. C. e MELGAÇO R. G. (orgs) $O$ bebê e as palavras: uma visão transdisciplinar sobre o bebê. Instituto Langage, 2013.

CISMARESCO, A. S. O grito neonatal e suas funções. (seção: o grito e as reações fisiológicas e emocionais das mães). In: BUSNEL, M. C. A linguagem dos bebês. São Paulo, Escuta ed., 1997.

CORIAT, E. Os flamantes bebês e a velha psicanálise. Estilos da Clínica. V.5, n.8, 2000.

FARIAS, C. N. F. e GOMES DE LIMA, G. Relação mãe-criança: esboço de um percurso na teoria psicanalítica. Revista Estilos da Clínica, ano IX, n. 16, 2004.

FÉDIDA, P. Le conte et la zone de l'endormissement. In: Corps de vide et espace de séance. Paris, Jean Pierre Delaye, 1977.

FOLINO, C. S. G. e LOPES DE SOUZA, AS. As Reverberações do encontro mãebebê: sobre a depressão e a depressividade pós-parto. In: BUSNEL, M. C. E MELGAÇO, R. G. (orgs) $O$ bebê e as palavras: uma visão transdisciplinar sobre o bebê. Instituto Langage, 2013.

GeiB, L. T. C., CATALdo Neto,A, WAinBerg R, NUNES ML. Sono e envelhecimento. Rev. Psiquiatria. Rio Gd. Sul, 25(3):453-465, 2003.

RC: 98238

Доступно в:

https://www.nucleodoconhecimento.com.br/психология/символическая-связь 
GEIB, L. T. C. Desenvolvimento dos estados do sono na infância. Revista Brasileira de Enfermagem, 60(3):323-26, 2007.

GROMANN, R. M. G. Sonho e psiquismo: o labirinto entre o corpo e a subjetividade. Pulsional Revista de psicanálise, 164: 27-34, 2002

JERUSALINSKY, A. Psicanálise e desenvolvimento infantil. Porto alegre, Artes e Ofícios, 2004.

JOHN, M. W. Sensitivity and specificity of the multiple sleep latency test (MSLT), the maintenance of wakefulness test and the Epworth sleepiness scale: failure of the MSLT as a gold standard. J. Sleep Res, 9: 5-11, 2000.

LAZNIK-PENOT, M. C. Rumo à palavra. São Paulo, Escuta ed., 1997.

LAZNIK-PENOT, M. C. Linguagem e comunicação do bebê de zero a três meses. In: LAZNIK-PENOT, M. C. A hora e a vez do bebê. Instituto Langage, 2013.

LEITE, C. A. O. Quando o corpo pede um nome. Tese de doutorado, Instituto de Estudos da Linguagem, UNICAMP, 2008.

MADEIRA, I. R. e AQUINO, L. A. Problemas de abordagem difícil: "não come" e "não dorme". J Pediatr, 79 (Supl 1): 43-54, 2003.

MELGAÇO, R. G. Prefácio. In: BUSNEL, M. C. e MELGAÇO, R. G. (orgs) O bebê e as palavras. São Paulo, Instituto Langage, 2013.

PALLADINO, R. R. R.; CUNHA, M.C. e SOUZA, L. A. P. Transtornos de linguagem e transtornos de alimentação em crianças. Revista Psicanálise e Universidade, 21: 95-108, 2004.

$\mathrm{RC}: 98238$ 
PALLADINO, R. R. R.; CUNHA, M.C. e SOUZA, L. A. P. Transtornos de linguagem e de alimentação: coincidências ou co-ocorrências? Pró-fono Revista de Atualização Científica, 19, 205-214, 2007.

PALLADINO RRR. Linguagem e sono. Anais do XXIV Congresso Brasileiro de Fonoaudiologia, Sociedade Brasileira de Fonoaudiologia, São Paulo, 2016

PALLADINO RRR. Sono e alimentação: funções psíquicas associadas. Anais do III Congresso Iberoamericano de Fonoaudiologia e XXVI Congresso Brasileiro de Fonoaudiologia. Sociedade Brasileira de Fonoaudiologia, Curitiba, 2018.

PENHA, N. C. G. Dormir nos braços da mãe: a primeira guardiã do sono. Rev Psichê, 6(10):65-84, 2002.

PIAULINO DE ARAÚJO, P. D. Validação do questionário do sono infantil de Reimão e Lefèvre (QRL). Tese de doutorado, Departamento de Neurologia, USP, 2012.

RÉÉDUCATION ORTHOPHONIQUE, 44 année, juin/2006, trimestriel n. 226 - La deglutition Dysfunctionnelle, 2006.

SANTOS, M. C. Problemas alimentares da infância sem diagnóstico clínico: quando vigiar, quando atuar? Rev. Hospital de Crianças Maria Pia, vol. XIII, n.4: 342-7, 2004.

SERVILHA, B. e RAAD BUSSAB, V.S. Interação Mãe-Criança e Desenvolvimento da Linguagem: a Influência da Depressão Pós-Parto. Psico, Porto Alegre, v. 46, n. 1, pp. 101-109, jan.-mar. 2015.

SPINOZA, B. Ética. Trad. e notas de Thomaz Tadeu. Belo Horizonte, Autêntica Ed. 2007.

RC: 98238

Доступно в:

https://www.nucleodoconhecimento.com.br/психология/символическая-связь 
STORK, H.; LY, O. e MOTA. G. Os bebês falam: como você os compreende? Uma comparação intercultural. In: BUSNEL, M. C. (org) A linguagem dos bebês. Sabemos escutá-los? São Paulo: Escuta Ed., 1997.

THIBAULT, C. A língua, órgão chave das oralidades. Rééducation Orthophonique, 44 année, juin/2006, trimestriel, n.226 - La deglutition Dysfunctionnelle, p.115, 2006.

VORCARO, A. Crianças em Psicanálise, Rio de Janeiro, Companhia de Freud, 2005.

WINNICOTT, D. W. Pensando sobre crianças. Porto Alegre, Artmed, 1975.

Представлено: Сентябрь 2021 года.

Утвержден: Сентябрь 2021 года.

RC: 98238

Доступно в:

https://www.nucleodoconhecimento.com.br/психология/символическая-связь 